\title{
A influência da temperatura nas transformações de fases dos minerais presentes na lama vermelha: redução da hematita à magnetita
}

\section{The influence of temperature on phase transformations of the minerals present in the red mud: reduction of hematite to magnetite}

Bruno Marques Viegas ${ }^{1}$, Edilson Marques Magalhães ${ }^{2}$, José Antônio da Silva Souza ${ }^{2}$, Emanuel Negrão Macêdo ${ }^{2}$

\footnotetext{
${ }^{1}$ Programa de Pós-Graduação em Engenharia de Recursos Naturais da Amazônia - PRODERNA - ITEC/UFPA CEP: 66075-110, Belém, PA, Brasil.

e-mail: bviegas@ufpa.br

${ }^{2}$ Faculdade de Engenharia Química - FEQ - ITEC/UFPA CEP: 66075-110, Belém, PA, Brasil.

e-mail: magalhaes@ufpa.br, jass@ufpa.br, enegrao@ufpa.br
}

\section{RESUMO}

Neste trabalho foi proposta uma rota tecnológica visando analisar o comportamento das transformações de fases dos minerais presentes na lama vermelha durante o processo de redução da hematita à magnetita. As análises de fluorescência e difração de raios X mostraram que a lama vermelha apresentou em sua composição aproximadamente $5 \%$ de óxido de titânio como anatásio e $28 \%$ de óxido de ferro, nas formas de hematita e goethita. Foram realizados experimentos envolvendo a redução da hematita à magnetita utilizando tratamento térmico. O material foi calcinado nas temperaturas de 500, 600 e $1000{ }^{\circ} \mathrm{C}$ durante $2 \mathrm{~h}$. Em seguida, foram realizadas análises de difração de raios X e espectroscopia Raman, as quais mostraram que a hematita foi reduzida à magnetita em todas as condições experimentais. Para as temperaturas de calcinação de 500 e $600{ }^{\circ} \mathrm{C}$, o óxido de titânio permaneceu na forma livre de anatásio, porém para a calcinação realizada a 1000 ${ }^{\circ} \mathrm{C}$, o óxido passou para a forma combinada com ferro (ilmenita). A rota proposta neste trabalho possibilitou a obtenção de um material com características magnéticas, o qual poderá ser utilizado como fonte de titânio após a extração dos compostos de ferro por separação magnética ou lixiviação ácida.

Palavras-chave: Lama vermelha, ferro, titânio.

\section{ABSTRACT}

In this work a technological route was proposed to analyze the behavior of phase transformations of the minerals present in the red mud during the process of reduction of hematite to magnetite. The fluorescence analysis and X-ray diffraction showed that red mud presented approximately 5\% titanium oxide as anatase and $28 \%$ iron oxide in the forms of hematite and goethite. Experiments involving the reduction of hematite to magnetite using thermal treatment. The material was calcined at temperatures of 500, 600 and $1000{ }^{\circ} \mathrm{C}$ for 2 h. Then, X-ray diffraction and Raman spectroscopy analyzes were performed, which showed that the hematite was reduced to magnetite in all experimental conditions. For the calcination temperatures of 500 and $600{ }^{\circ} \mathrm{C}$, the titanium oxide remained in anatase free form, but for the calcination performed at $1000{ }^{\circ} \mathrm{C}$, the oxide passed into the form combined with iron (ilmenite). The route proposed in this work allowed to obtain a material with magnetic characteristics, which could be used as source of titanium after extraction of iron compounds by magnetic separation or acid leaching.

Keywords: Red mud, Iron, Titanium.

\section{INTRODUÇÃO}

O resultado proveniente da atividade produtiva de algumas indústrias do setor primário, tais como a siderúr- 
gica, metalúrgica e a de alumínio, vem acompanhado, não só do produto de interesse industrial, mas também da geração de uma grande quantidade de resíduos, que na maioria das vezes são depositados em ambientes próximos às fábricas, devido ao elevado custo que o transporte e tratamento representam para a indústria. Em alguns casos, esses resíduos são agressivos e tóxicos ao meio ambiente, podendo contaminar os solos e os lençóis freáticos se não forem armazenados de forma correta [1].

Embora a produção de alumina tenha uma grande importância socioeconômica para a região Amazônica Brasileira, como em qualquer outra área, gera uma grande quantidade de resíduo [2]. Esse resíduo, também conhecido como lama vermelha, possui características multicomponentes, sendo formado basicamente por óxidos insolúveis de ferro, silício, aluminossilicatos de sódio, carbonatos e aluminatos de cálcio e dióxido de titânio [3].

A lama vermelha não é considerada perigosa, mas em função da sua elevada alcalinidade e da grande quantidade produzida, cujo armazenamento requer grande área para sua disposição, pode provocar danos ambientais se lixiviada até os corpos de água subterrâneos [4]. Desta forma, propor uma utilização para este resíduo é preocupação constante, pois dada a produção regional que é de milhões de toneladas anuais, é imperativo que se chegue a uma destinação adequada. Devido ao óxido de ferro estar presente em maior quantidade na lama vermelha, muitos trabalhos são reportados na literatura visando a obtenção desse óxido.

WAN-CHAO et al. [5] obtiveram ferro a partir da hematita $\left(\mathrm{Fe}_{2} \mathrm{O}_{3}\right)$ e limonita $\left(\mathrm{FeO}(\mathrm{OH}) \cdot{ }_{\mathrm{n}} \mathrm{H}_{2} \mathrm{O}\right)$ presentes na lama vermelha. LIU et al. [6] reduziram o óxido de ferro presente na lama vermelha através da calcinação da mistura de lama vermelha, carbono e aditivos. XIAO-BIN et al. [7] mostraram que através de análises termodinâmicas é possível reduzir a hematita à magnetita, a partir de uma mistura de lama vermelha, carbonato de sódio $\left(\mathrm{Na}_{2} \mathrm{CO}_{3}\right)$, calcário $\left(\mathrm{CaCO}_{3}\right)$ e carbono $(\mathrm{C})$. QUN-HU e YAN [8] realizaram um estudo experimental de obtenção de ferro a partir da lama vermelha com a adição de carvão em pó. RAO et al. [9] realizaram a redução do óxido de ferro da lama vermelha com o auxílio de sulfato de sódio e carbonato de sódio. Através de um processo de calcinação sob atmosfera de nitrogênio, LIU et al. [10] reduziram a hematita utilizando a pirita $\left(\mathrm{FeS}_{2}\right)$ como agente redutor.

Uma possível alternativa de reaproveitamento do resíduo está centrada em promover a concentração do titânio na lama vermelha, a qual pode ser realizada, através da redução da hematita à magnetita e posterior separação magnética ou lixiviação ácida dos óxidos de ferro. Para isso, primeiramente, é necessário que se realize um estudo acerca das variáveis que regem o processo de redução da hematita e das transformações minerais que ocorrem com o titânio durante esse processo. Sendo assim, este trabalho teve como foco principal propor uma rota tecnológica para redução da hematita à magnetita utilizando tratamento térmico.

\section{MATERIAIS E MÉTODOS}

$\mathrm{Na}$ elaboração deste trabalho foram utilizadas como matérias-primas a lama vermelha e o carvão vegetal. A lama vermelha utilizada nos experimentos foi cedida por uma empresa localizada na região Amazônica Brasileira, estado do Pará. Já o carvão utilizado é o de origem vegetal, com características descritas a seguir.

Na Figura 1 pode ser observado um esquema simplificado das etapas do procedimento experimental. 


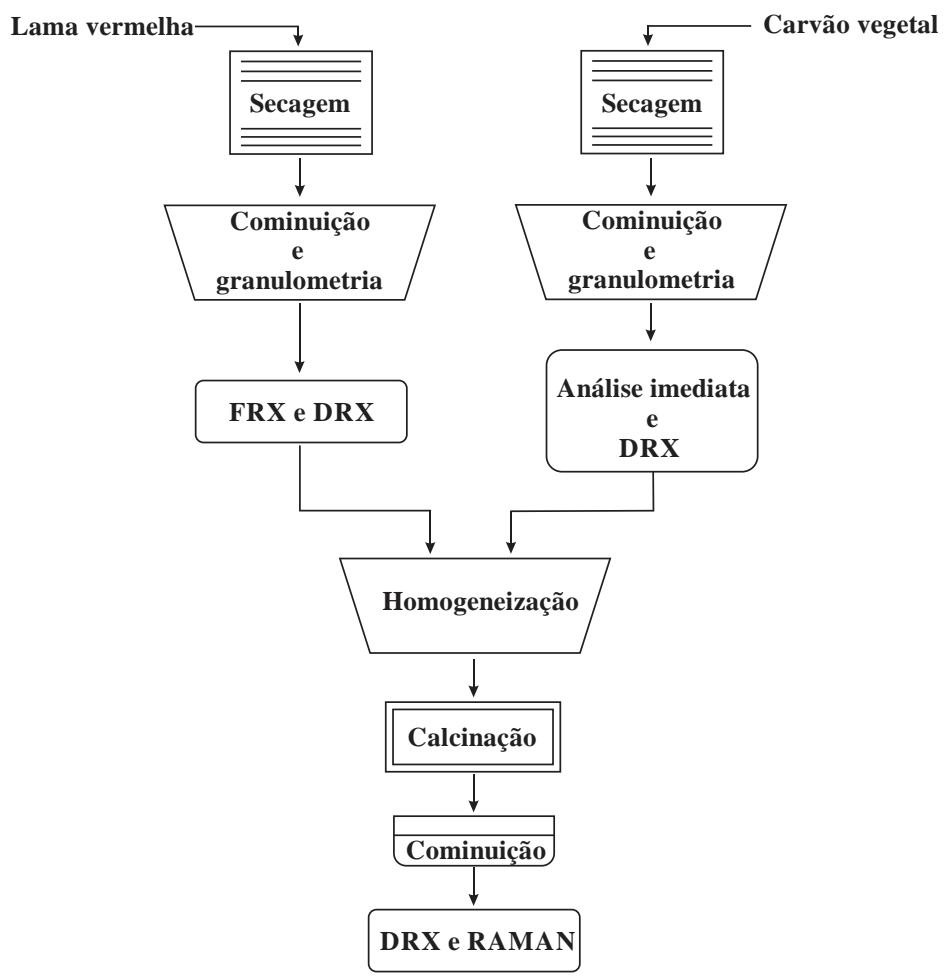

Figura 1: Fluxograma do procedimento experimental.

De acordo com a Figura 1, antes de iniciar o processo de calcinação, há o preparo das matérias-primas, onde a lama vermelha (LV) foi seca em um secador de bandejas à $105^{\circ} \mathrm{C}$ durante $24 \mathrm{~h}$, com a finalidade de remover o excesso de umidade que havia no material. Após à obtenção do material seco, foi realizada a cominuição em moinho de bolas (marca CIMAQ S.A, modelo Work Index série 005), durante 30 min, assim havendo a desagregação do material. A granulometria da lama vermelha foi ajustada para partículas menores que $150 \mu \mathrm{m}$. Após o ajuste, a LV foi analisada com as técnicas de fluorescência e difração de raios X.

O carvão vegetal $(\mathrm{CV})$ também passou por um pré-tratamento antes do processo de calcinação, conforme pode ser observado no fluxograma da Figura 1. Após ser adquirido, o carvão vegetal foi levado à estufa a $105{ }^{\circ} \mathrm{C}$ por $24 \mathrm{~h}$. Com o material seco, foi realizada a cominuição em moinho de discos, durante 45 min, resultando em partículas menores que $1,70 \mathrm{~mm}$. Em seguida, foi realizada a análise imediata e a difração de raios X. A análise imediata do carvão vegetal teve como objetivo determinar os teores de umidade, cinza, matérias voláteis e carbono fixo presentes no material. Essa análise foi realizada segundo a normatização brasileira [11].

Desta forma, após o pré-tratamento e caracterização das matérias-primas, essas foram misturadas (com o auxílio de um moinho de bolas) de acordo com as porcentagens estabelecidas na Tabela 1, onde M.MISTURA representa a massa total da mistura.

Tabela 1: Composição das misturas.

\begin{tabular}{l|l|l|l}
\hline MISTURA & LV (\%) & CV (\%) & M.MISTURA (G) \\
\hline 1 & 30 & 70 & 100 \\
\hline 2 & 40 & 60 & 100 \\
\hline 3 & 50 & 50 & 100 \\
\hline 4 & 60 & 40 & 100 \\
\hline 5 & 70 & 30 & 100 \\
\hline
\end{tabular}

Para avaliar a influência da temperatura, os experimentos foram realizados em diferentes valores desta grandeza. Segundo KRIMPALIS et al. [12], só são observadas mudanças significativas na magnetização da lama vermelha em temperaturas a partir de $500^{\circ} \mathrm{C}$. Portanto, para o presente trabalho, foi utilizada uma faixa de temperatura que teve como valor mínimo $500^{\circ} \mathrm{C}$ e um valor máximo de $1000^{\circ} \mathrm{C}$, pois conforme observa- 
do por XIAO-BIN et al. [7], para temperaturas a partir de $1000{ }^{\circ} \mathrm{C}$, o equilíbrio para a reação de gaseificação do carbono tende a se estabelecer, no sentido de possuir apenas $\mathrm{CO}$ na sua composição gasosa. Portanto, terminado o processo de homogeneização, cada mistura foi colocada em um cadinho de níquel e levada à mufla, onde foi calcinada durante $2 \mathrm{~h}$.

O tempo de calcinação utilizado nos experimentos está baseado no trabalho de MISHRA et al. [13], o qual os autores afirmaram que o tempo aproximado pode variar de acordo com a natureza da lama vermelha utilizada, porém de uma forma geral, pode-se afirmar que a completa redução pode ser alcançada com aproximadamente 2 h de calcinação.

As análises de difração de raios $\mathrm{X}$ foram realizadas no Laboratório de Caracterização Mineral (LCM) do Instituto de Geociências da Universidade Federal do Pará (UFPA). As amostras foram analisadas em um difratômetro de raios X modelo X'PERT PRO MPD (PW 3040/60) da PANalytical, com goniômetro PW3050/60 (teta-teta), tubo de raios X de Co. Foram utilizadas as seguintes condições: faixa angular de varredura entre 4 e $75^{\circ}(2 \Theta)$, voltagem $40 \mathrm{kV}$ e corrente $30 \mathrm{~mA}$; tamanho do passo de $0,02^{\circ}(2 \Theta)$, e tempo/passo de $20 \mathrm{~s}$, fenda divergente de $1 / 4^{\circ}$, máscara de $10 \mathrm{~mm}$ e rotação com $1 \mathrm{rps}$.

As análises de fluorescência de raios $\mathrm{X}$ foram realizadas no Laboratório de Caracterização Mineral do Instituto de Geociências da UFPA. As amostras foram analisadas utilizando um espectrômetro WDS sequencial, modelo Axios Minerals da marca PANalytical, com tubo de raios X cerâmico, anodo de ródio (Rh) e máximo nível de potência, $2,4 \mathrm{~kW}$. A análise ocorreu da seguinte maneira: foi preparado um disco fundido em que foram pesados $1 \mathrm{~g}$ da amostra $+6 \mathrm{~g}$ de fundente (tetraborato de lítio $-\mathrm{Li}_{2} \mathrm{~B}_{4} \mathrm{O}_{7}$ ). Em seguida, a mistura foi fundida a $1000{ }^{\circ} \mathrm{C}$ por $10 \mathrm{~min}$, onde foi possível obter o valor da perda ao fogo (P.F).

As análises de espectroscopia Raman foram realizadas no Laboratório de Física Pesquisa da UFPA em um equipamento da marca HORIBA, modelo iHR 320. Para a realização das medidas, foi utilizado um laser com comprimento de onda de excitação de $633 \mathrm{~nm}$. Após incidir na amostra, a luz emitida pelo laser é espalhada no material e em seguida é conduzida até o espectrômetro do sistema. O sinal gerado, após o espalhamento na amostra, é codificado no espectrômetro e depois é coletado por uma câmera CCD Synapse, a qual transmite os dados para o computador, que por meio de um software os dados são interpretados. Essas análises tiveram como principal objetivo avaliar as transformações minerais que ocorreram com o óxido de titânio após o processo de calcinação.

\section{RESULTADOS E DISCUSSÃO}

\subsection{Fluorescência de raios $X$}

A análise por fluorescência de raios $\mathrm{X}$ foi realizada com o propósito de quantificar os compostos de ferro e titânio presentes na LV antes do processo de calcinação. Desta forma, a Tabela 2 apresenta a composição química da lama vermelha antes do tratamento térmico.

Tabela 2: Composição química da lama vermelha obtida pela fluorescência de raios X.

\begin{tabular}{l|l}
\hline COMPOSTOS & \% EM MASSA \\
\hline $\mathrm{Fe}_{2} \mathrm{O}_{3}$ & 28,68 \\
\hline $\mathrm{Na}_{2} \mathrm{O}$ & 13,44 \\
\hline $\mathrm{TiO}_{2}$ & 5,63 \\
\hline $\mathrm{CaO}$ & 1,62 \\
\hline $\mathrm{SiO}_{2}$ & 18,29 \\
\hline $\mathrm{Al}_{2} \mathrm{O}_{3}$ & 22,76 \\
\hline $\mathrm{K}_{2} \mathrm{O}$ & $<0,10$ \\
\hline $\mathrm{P}_{2} \mathrm{O}_{5}$ & 0,10 \\
\hline $\mathrm{SO}_{3}$ & 0,12 \\
\hline $\mathrm{MnO}_{2}$ & 0,17 \\
\hline $\mathrm{P.F}^{\mathrm{F}}$ & 9,10 \\
\hline
\end{tabular}

Na Tabela 2 fica evidente o elevado teor de óxido de ferro (28,68\% em massa) na lama vermelha, o qual justifica o desenvolvimento de uma técnica que possibilite a recuperação desse composto. Pode ser ob- 
servado ainda um teor de óxido de sódio de 13,44\% em massa, responsável pela elevada alcalinidade no resíduo $(\mathrm{pH}>11$ ) [14], bem como um percentual de 5,63\% em massa de óxido de titânio, o qual pode ser elevado com a extração do ferro, fornecendo, desta forma, um material concentrado em titânio.

\subsection{Análise imediata do carvão vegetal}

A Tabela 3 apresenta a análise imediata realizada no carvão vegetal referente à quantidade de carbono fixo (CF), cinzas (CZ), matérias voláteis (MV) e umidade (U) [15].

Tabela 3: Análise imediata do carvão vegetal.

\begin{tabular}{l|l}
\hline ANÁLISE & \% EM MASSA \\
\hline CF & 65,28 \\
\hline CZ & 19,48 \\
\hline MV & 15,24 \\
\hline U & 4,71 \\
\hline
\end{tabular}

A análise imediata apresentada na Tabela 3 mostra que o carvão vegetal utilizado nos experimentos apresenta em sua composição 65,28\% em massa de carbono fixo. Por ser fonte de carbono, o carvão vegetal atuará como reagente no processo de redução da hematita à magnetita [7]. Geralmente é aceito que a redução do óxido de ferro pelo carbono ocorre através dos gases intermediários $\mathrm{CO}$ e $\mathrm{CO}_{2}$, de acordo com o seguinte mecanismo: o carbono reage com o oxigênio do ar, Equação 1, mais o oxigênio proveniente da dissolução dos óxidos de ferro, Equação 2, formando CO. A reação sólido-sólido (óxido de ferro + carbono), apesar de em pequena quantidade, também contribui para a formação de CO. A partir da formação de CO, haverá propagação da reação de redução dos óxidos de ferro, segundo as Equações 3, 4 e 5. A reação de gaseificação do carbono através do $\mathrm{CO}_{2}$, Equação 6, transformando-o em monóxido, é conhecida como Reação de Boudouard e constitui uma etapa fundamental em processos de redução dos óxidos de ferro [16].

$$
\begin{aligned}
& \mathrm{C}_{(s)}+\frac{1}{2} \mathrm{O}_{2(g)} \rightarrow \mathrm{CO}_{(g)} \\
& \mathrm{C}_{(s)}+\mathrm{Fe}_{x} \mathrm{O}_{y(s)} \rightarrow \mathrm{Fe}_{x} \mathrm{O}_{y-1(s)}+\mathrm{CO}_{(g)} \\
& 3 \mathrm{Fe}_{2} \mathrm{O}_{3(s)}+\mathrm{CO}_{(g)} \Leftrightarrow 2 \mathrm{Fe}_{3} \mathrm{O}_{4(s)}+\mathrm{CO}_{2(g)} \\
& \mathrm{Fe}_{3} \mathrm{O}_{4(s)}+\mathrm{CO}_{(g)} \Leftrightarrow 3 \mathrm{FeO}_{(s)}+\mathrm{CO}_{2(g)} \\
& \mathrm{FeO}_{(s)}+\mathrm{CO}_{(g)} \Leftrightarrow \mathrm{Fe}_{(s)}+\mathrm{CO}_{2(g)} \\
& \mathrm{C}_{(s)}+\mathrm{CO}_{2(g)} \rightarrow 2 \mathrm{CO}_{(g)}
\end{aligned}
$$

Pelo fato dos gases resultantes serem gerados a partir de uma mistura adequada de $\mathrm{CO}$ e $\mathrm{CO}_{2}$, é importante estudar o efeito da concentração de carvão vegetal (carbono) no processo, pois a quantidade de $\mathrm{CO}$ e $\mathrm{CO}_{2}$ produzida está diretamente ligada à quantidade desta matéria-prima introduzida no processo. O carbono, proveniente do carvão, não reage com os óxidos de $\mathrm{Al}_{2} \mathrm{O}_{3}, \mathrm{SiO}_{2}, \mathrm{CaO}$ e $\mathrm{Na}_{2} \mathrm{O}$ presentes na lama vermelha [7].

\subsection{Difração de raios $X$}

As análises por difração de raios X permitiram a identificação das fases minerais presentes nos materiais antes e após o tratamento térmico. Através destas análises foi possível identificar as transformações minerais que ocorreram na lama vermelha após o processo, bem como as respectivas caracterizações das matériasprimas que foram utilizadas. A Figura 2 mostra a análise mineralógica para a lama vermelha (Figura 2a) e para o carvão vegetal (Figura 2b). 


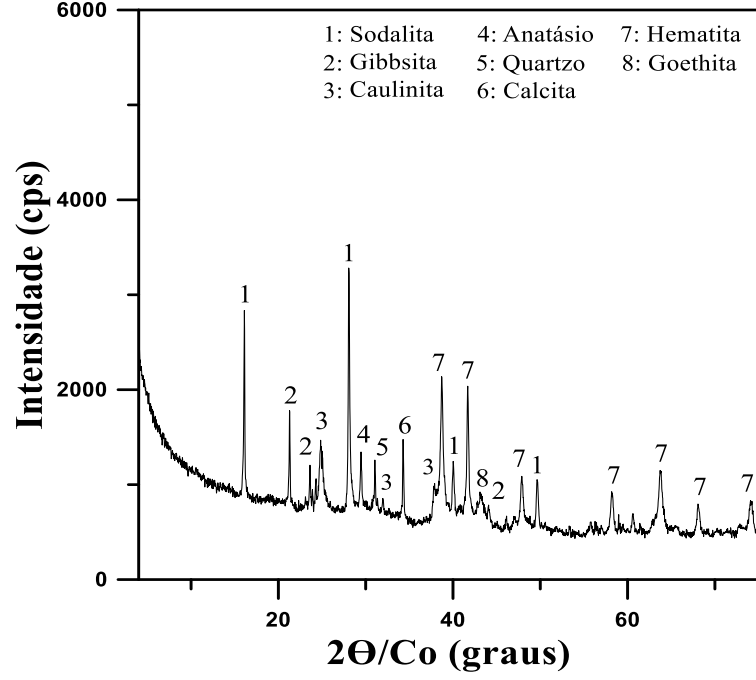

(a)

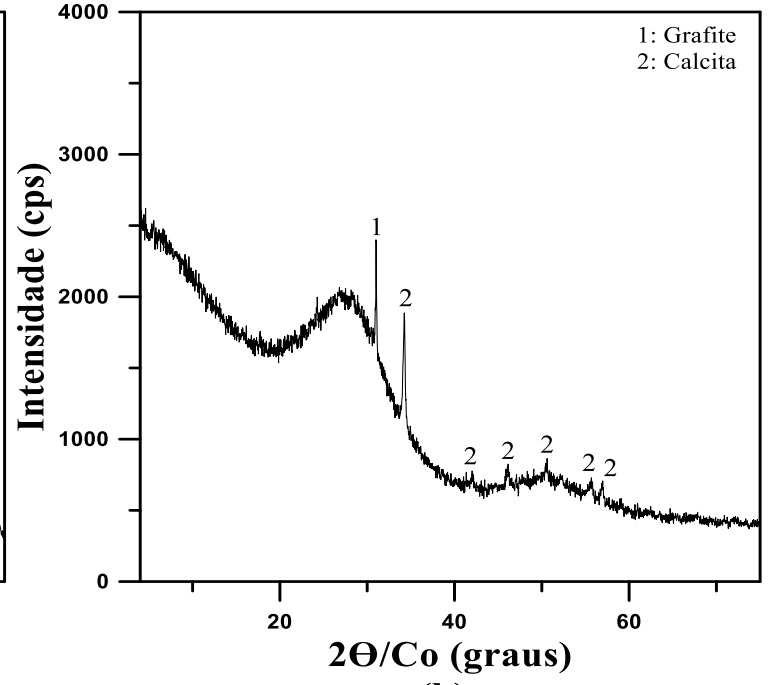

(b)

Figura 2: Difratograma da lama vermelha (a) antes do tratamento térmico (b) e do carvão vegetal.

A Figura 2a mostra os minerais presentes na lama vermelha em duas categorias: aqueles provenientes da própria bauxita, tais como a gibbsita $\left[\mathrm{Al}(\mathrm{OH})_{3}\right]$, hematita $\left(\alpha-\mathrm{Fe}_{2} \mathrm{O}_{3}\right)$, goethita $[\mathrm{FeO}(\mathrm{OH})]$, anatásio $\left(\mathrm{TiO}_{2}\right)$, quartzo $\left(\mathrm{SiO}_{2}\right)$, e caulinita $\left[\mathrm{Al}_{2}\left(\mathrm{Si}_{2} \mathrm{O}_{5}\right)(\mathrm{OH})_{4}\right]$, e numa segunda categoria, aqueles que são formados durante o processo Bayer, tais como a sodalita $\left[\mathrm{Na}_{8}\left(\mathrm{Al}_{6} \mathrm{Si}_{6} \mathrm{O}_{24}\right)\left(\mathrm{CO}_{3}\right)\left(\mathrm{H}_{2} \mathrm{O}\right)_{3}\right]$ e a calcita $\left(\mathrm{CaCO}_{3}\right)$ [17].

Fazendo uma comparação da Tabela 2 com a Figura 2a, observa-se que: o óxido de ferro está presente na forma de hematita e goethita. Já o óxido de titânio encontra-se somente na forma de anatásio; o óxido de alumínio encontra-se como gibbsita, caulinita e sodalita; e o óxido de silício como caulinita, sodalita e quartzo. Já os óxidos de cálcio e sódio, encontram-se somente nas formas de calcita e sodalita, respectivamente. Os outros elementos $\left(\mathrm{K}_{2} \mathrm{O}, \mathrm{P}_{2} \mathrm{O}_{5}, \mathrm{SO}_{3}\right.$ e $\left.\mathrm{MnO}_{2}\right)$ estão na forma de traços e, portanto, não são identificados pela difração de raios X.

$\mathrm{O}$ difratograma de raios $\mathrm{X}$ da Figura $2 \mathrm{~b}$ evidenciou as respectivas fases mineralógicas: carbono grafite e calcita. A presença do carbono grafite está relacionado com a constituição característica da matéria-prima, conforme apresentada na Tabela 3, já a calcita, está relacionada ao processo de fabricação do mesmo, apresentando-se como contaminante neste material.

A Figura 3 apresenta o difratograma da mistura que contém 30\% de lama vermelha (LV30\%). Essa mistura foi submetida a um tratamento térmico nas temperaturas de 500,600 e $1000^{\circ} \mathrm{C}$ durante $2 \mathrm{~h}$. O objetivo dessas análises foi o de avaliar a influência da temperatura na redução da hematita à magnetita para uma concentração fixa de carvão vegetal e lama vermelha.

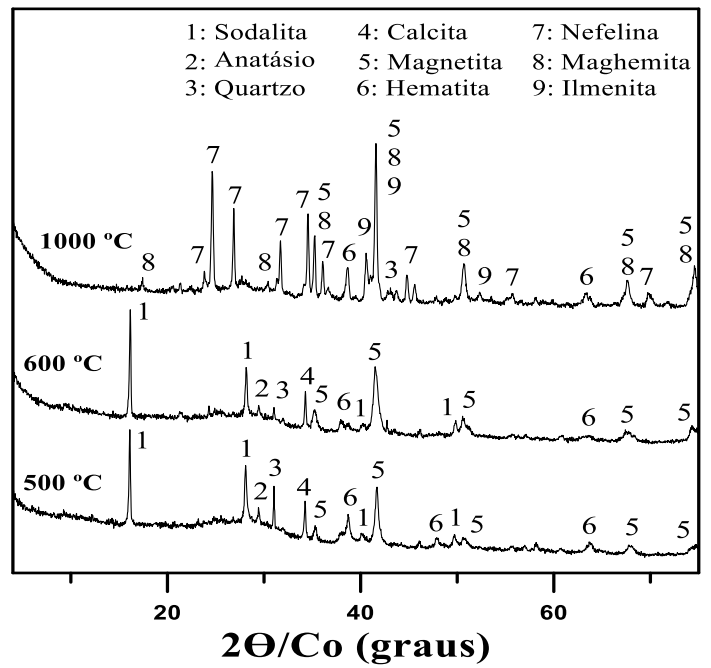

Figura 3: Difratograma do efeito da temperatura para a LV30\%. 
A partir da Figura 3, para as três temperaturas analisadas, pode-se observar que após o tratamento térmico houve a transformação das seguintes fases: gibbsita, goethita e caulinita. Entre 220 e $350{ }^{\circ} \mathrm{C}$ ocorre a decomposição da gibbsita [18]. Já em temperaturas superiores a $240{ }^{\circ} \mathrm{C}$, ocorre a decomposição da goethita em hematita $\left(\mathrm{Fe}_{2} \mathrm{O}_{3}\right)[19]$.

Na faixa de temperatura entre 476 e $663{ }^{\circ} \mathrm{C}$ ocorre a desidroxilação da caulinita e formação da metacaulinita segundo a Equação 7 abaixo [20]:

$$
\mathrm{Al}_{2} \mathrm{O}_{3} \cdot 2 \mathrm{SiO}_{2} \cdot 2 \mathrm{H}_{2} \mathrm{O} \rightarrow \mathrm{Al}_{2} \mathrm{O}_{3} \cdot 2 \mathrm{SiO}_{2}+2 \mathrm{H}_{2} \mathrm{O}_{(\mathrm{g})}
$$

A metacaulinita é um material formado a partir da transformação térmica da caulinita. E, devido ser um material amorfo, a mesma não é identificada pela difração de raios X. Esta faixa de temperatura de formação da metacaulinita pode variar dependendo da natureza do material estudado, sendo esta variação explicada pela diferença nos tamanhos das partículas de cada amostra, bem como sua cristalinidade [20].

Verifica-se também o aparecimento de quatro novas fases: magnetita $\left(\mathrm{Fe}_{3} \mathrm{O}_{4}\right)$ presente no difratograma de 500, 600 e $1000{ }^{\circ} \mathrm{C}$, maghemita $\left(\gamma-\mathrm{Fe}_{2} \mathrm{O}_{3}\right)$, presente no difratograma de $1000{ }^{\circ} \mathrm{C}$, nefelina $\left(\mathrm{Na}_{2} \mathrm{Al}_{2} \mathrm{Si}_{2} \mathrm{O}_{8}\right)$ e ilmenita $\left(\mathrm{FeTiO}_{3}\right)$, ambas também em $1000{ }^{\circ} \mathrm{C}$. A maghemita é termodinamicamente estável e não pode se transformar em hematita [12]. Já a formação da magnetita, está relacionada ao processo de redução da hematita.

A nefelina é formada durante o tratamento térmico, devido a lama vermelha apresentar quantidades consideráveis de óxidos de sódio e silício, tornando propícia a formação de espécies do tipo $\mathrm{Na}_{5} \mathrm{Al}_{3} \mathrm{Si}_{3} \mathrm{O}_{15}$, as quais são precursoras da nefelina [1].

Observa-se também nos difratogramas que o anatásio $\left(\mathrm{TiO}_{2}\right)$ está presente nas misturas calcinadas a 500 e $600{ }^{\circ} \mathrm{C}$, porém ao ser calcinada a $1000^{\circ} \mathrm{C}$, o titânio reage com o óxido de ferro presente na mistura dando origem a ilmenita $\left(\mathrm{FeTiO}_{3}\right)$. Portanto, para a temperatura de calcinação de $1000^{\circ} \mathrm{C}$, o titânio passa da forma livre (anatásio) para a forma combinada com o ferro (ilmenita).

Para a calcinação realizada a $1000^{\circ} \mathrm{C}$, nota-se também o desaparecimento das fases sodalita e calcita. $\mathrm{Na}$ faixa de temperatura entre 388 e $850^{\circ} \mathrm{C}$, uma sequência de eventos térmicos superpostos ocorre, os quais podem ser interpretados como a descarbonatação da calcita e sodalita [1].

Considerando ainda a calcinação realizada a $1000{ }^{\circ} \mathrm{C}$, parte da sodalita desidratada reage com restos de alumina e sílica amorfa em uma primeira etapa, contribuindo também para a formação da nefelina [1].

As Figuras 4 e 5 apresentam os difratogramas realizados nas misturas que contêm $40 \%$ de lama vermelha (LV40\%) (Figura 4a), 50\% de lama vermelha (LV50\%) (Figura 4b), 60\% de lama vermelha (LV60\%) (Figura 5a) e 70\% de lama vermelha (LV70\%) (Figura 5b). Essas misturas foram submetidas a um tratamento térmico nas temperaturas de 500,600 e $1000{ }^{\circ} \mathrm{C}$ durante $2 \mathrm{~h}$.

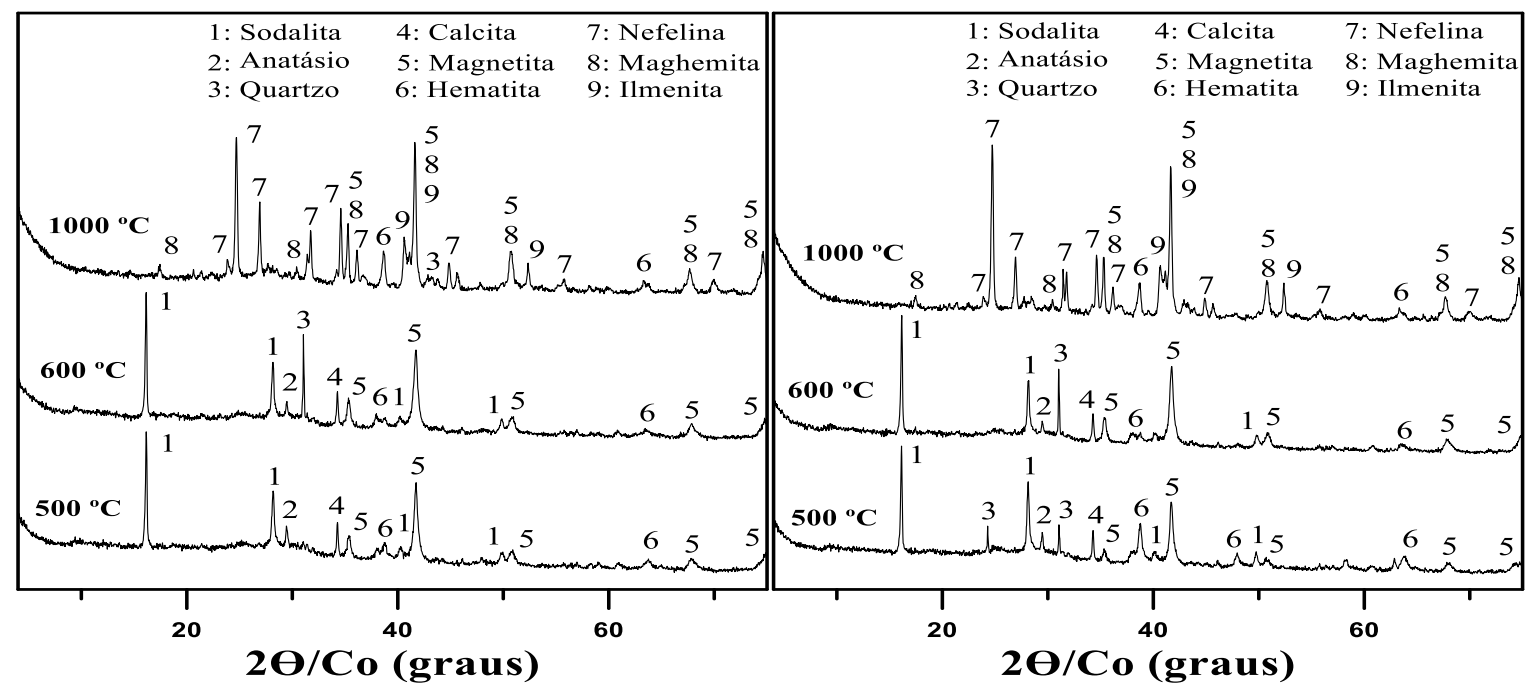

(a)

(b)

Figura 4: Difratograma do efeito da temperatura para a (a) LV40\% e (b) LV50\%. 


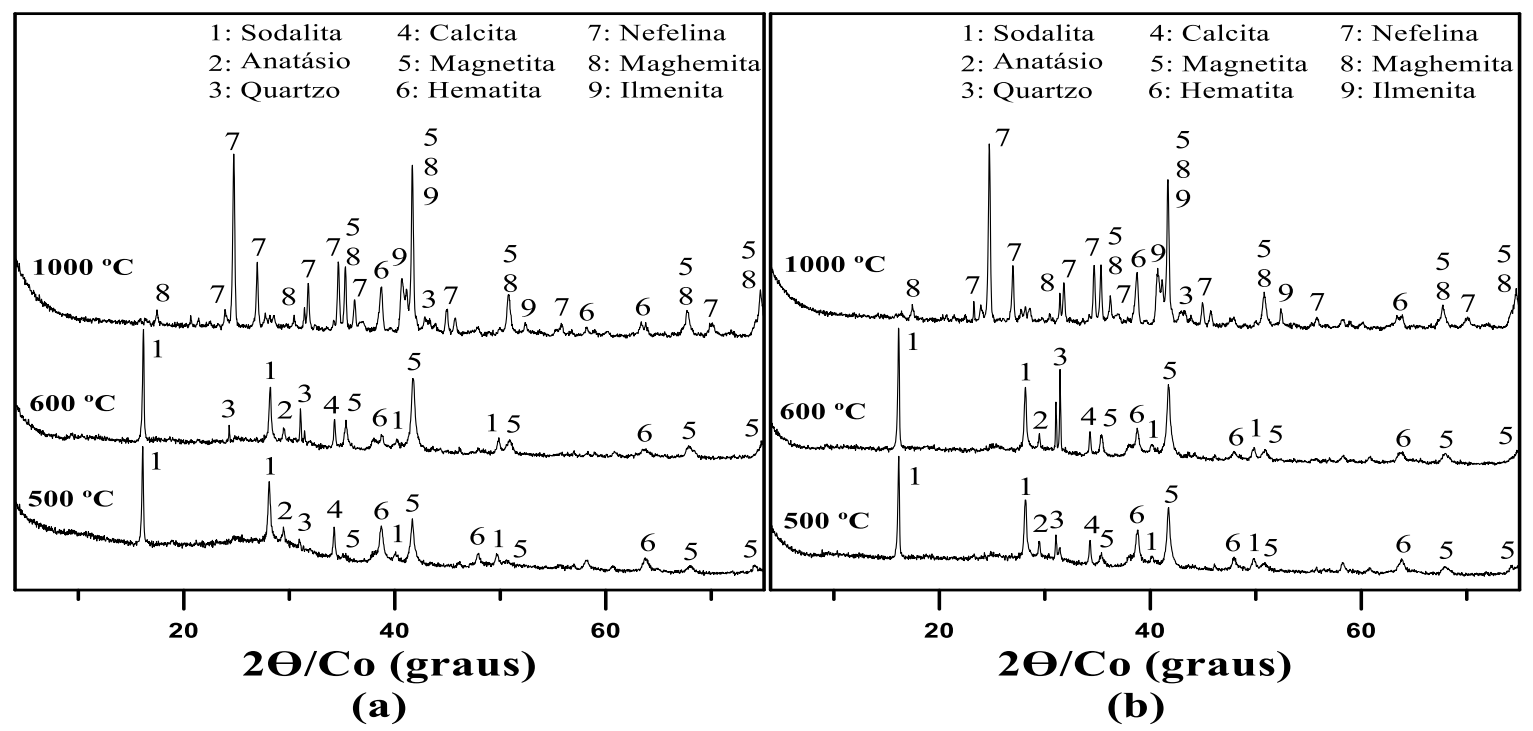

Figura 5: Difratograma do efeito da temperatura para a (a) LV60\% e (b) LV70\%.

Verifica-se nas Figuras 4 e 5 que os difratogramas têm comportamentos similares aos da Figura 3. Para as temperaturas de 500 e $600{ }^{\circ} \mathrm{C}$, nota-se a presença dos seguintes minerais: sodalita, anatásio, calcita, magnetita, hematita e quartzo. A presença do mineral de magnetita pode ser confirmada nos difratogramas devido à presença dos picos em 35,496; 41,781 e 67,884 graus, os quais são característicos do mineral. Já a identificação do anatásio, para as misturas calcinadas a 500 e $600{ }^{\circ} \mathrm{C}$, pode ser confirmada pela presença do pico em 29,4806 graus. Porém, para as misturas calcinadas a $1000^{\circ} \mathrm{C}$, nota-se o desaparecimento deste pico, uma vez que nessa temperatura o titânio reage com o ferro dando origem a ilmenita.

Para a temperatura de $1000{ }^{\circ} \mathrm{C}$, tem-se a presença dos seguintes minerais: maghemita, quartzo, nefelina, magnetita, hematita e ilmenita. A identificação do mineral de maghemita pode ser confirmada nos difratogramas devido à presença dos picos em 17,49 e 30,54 graus, que são picos característicos do mineral. Já a identificação da ilmenita pode ser confirmada pela presença dos picos em 40,67 e 52,36 graus.

Pode ser observado também o aumento na intensidade dos picos de magnetita com o aumento da temperatura. Esse aumento está baseado na reação de Boudouard, uma vez que esta reação é endotérmica [21], o aumento da temperatura faz com que ocorra uma maior formação de CO e consequentemente maior eficiência no processo de redução da hematita à magnetita. Portanto, à medida que a reação avança no sentido de formação de magnetita, a concentração de hematita diminui. Entretanto, ainda permanece uma pequena quantidade de hematita na mistura. Essa quantidade é proveniente da parte que não foi completamente reduzida à magnetita e também não se transformou em maghemita.

De uma forma geral, pode-se afirmar que, no que diz respeito a formação ou desaparecimento de novas fases, as concentrações de carvão vegetal avaliadas nos experimentos não tiveram efeito significativo, pois os difratogramas apresentaram comportamento similares, com poucas diferenças nas intensidades dos picos.

Na Tabela 4 são apresentadas as formulações de cada mineral, assim como os cartões do banco de dados no PDF-ICDD (Powder Diffraction File - International Center for Diffraction Data) utilizados para as identificações das fases cristalinas.

Tabela 4: Formulações e cartões utilizados na difração de raios X para a identificação dos minerais.

\begin{tabular}{l|l|l}
\hline FASE MINERAL & FORMULAÇÃO & PDF-ICDD \\
\hline Anatásio & $\mathrm{TiO}_{2}$ & $00-001-0562$ \\
\hline Calcita & $\mathrm{CaCO}_{3}$ & $00-001-0837$ \\
\hline Caulinita & $\mathrm{Al}_{2}\left(\mathrm{Si}_{2} \mathrm{O}_{5}\right)(\mathrm{OH})_{4}$ & $01-072-2300$ \\
\hline Gibbsita & $\mathrm{Al}(\mathrm{OH})_{3}$ & $00-007-0324$ \\
\hline Goethita & $\mathrm{FeO}(\mathrm{OH})$ & $00-002-0281$ \\
\hline Hematita & $\alpha-\mathrm{Fe}_{2} \mathrm{O}_{3}$ & $00-033-0664$ \\
\hline
\end{tabular}




\begin{tabular}{l|l|l}
\hline Ilmenita & $\mathrm{FeTiO}_{3}$ & $01-083-0192$ \\
\hline Maghemita & $\gamma-\mathrm{Fe}_{2} \mathrm{O}_{3}$ & $00-025-1402$ \\
\hline Magnetita & $\mathrm{Fe}_{3} \mathrm{O}_{4}$ & $01-075-0449$ \\
\hline Nefelina & $\mathrm{Na}_{2} \mathrm{Al}_{2} \mathrm{Si}_{2} \mathrm{O}_{8}$ & $01-083-2279$ \\
\hline Quartzo & $\mathrm{SiO}_{2}$ & $01-085-0795$ \\
\hline Sodalita & $\mathrm{Na}_{8}\left(\mathrm{Al}_{6} \mathrm{Si}_{6} \mathrm{O}_{24}\right)\left(\mathrm{CO}_{3}\right)\left(\mathrm{H}_{2} \mathrm{O}\right)_{3}$ & $01-085-2066$ \\
\hline
\end{tabular}

\subsection{Espectroscopia Raman}

Devido o objetivo geral do trabalho ser a redução da hematita à magnetita visando a concentração do titânio na LV, torna-se necessário que seja realizado um estudo das transformações minerais que ocorreram com o titânio durante o tratamento térmico. Dessa forma, as análises por espectroscopia Raman tiveram como propósito estudar as transformações que ocorrem com o óxido de titânio após o processo de calcinação. A Figura 6 apresenta o efeito da temperatura de calcinação nas tranformações minerais da lama vermelha para a mistura que contém $30 \%$ de lama vermelha.

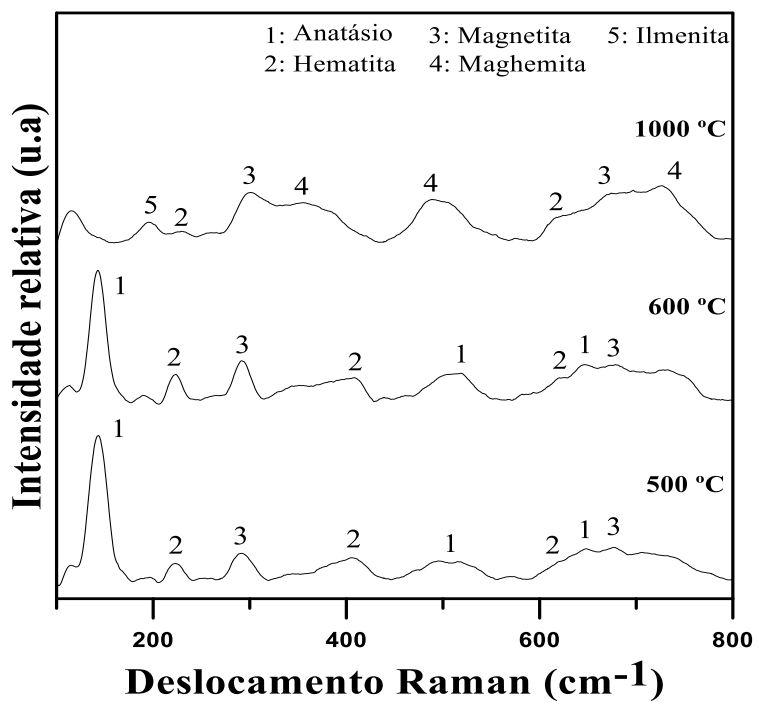

Figura 6: Espectro Raman do efeito da temperatura para a LV30\%.

Os espectros da Figura 6 apresentam as bandas dos minerais de anatásio, hematita, magnetita e maghemita na região estudada de 0 a $800 \mathrm{~cm}^{-1}$. A banda intensa em $145 \mathrm{~cm}^{-1}$ é característica da ligação O-Ti-O do mineral anatásio. A confirmação da presença do anatásio pode ser dada também pelos dois outros modos ativos em 515 e $640 \mathrm{~cm}^{-1}$, os quais são característicos desse mineral [22]. Desta forma, para as misturas calcinadas a 500 e $600{ }^{\circ} \mathrm{C}$, verifica-se que o titânio está presente na forma livre, ou seja, apresenta-se como mineral de anatásio $\left(\mathrm{TiO}_{2}\right)$. No entanto, quando essa mesma mistura é calcinada a $1000{ }^{\circ} \mathrm{C}$, nota-se o desaparecimento desses modos ativos $\left(145,515\right.$ e $\left.640 \mathrm{~cm}^{-1}\right)$ e o aparecimento de uma banda de ilmenita em $190 \mathrm{~cm}^{-1}$ [23]. Portanto, para a temperatura de calcinação de $1000^{\circ} \mathrm{C}$, o titânio passa da forma livre de anatásio para a forma combinada com o ferro, mais especificamente a ilmenita $\left(\mathrm{FeTiO}_{3}\right)$.

As análises dos espectros também mostraram a presença de bandas características da magnetita em 295 e $670 \mathrm{~cm}^{-1}$ [24]. A presença dessas bandas confirmaram que a hematita foi reduzida à magnetita durante o tratamento térmico para as três temperaturas estudadas. Nota-se também que para a calcinação realizada a $1000{ }^{\circ} \mathrm{C}$ houve o aparecimento da maghemita, com modos ativos em 500 e $720 \mathrm{~cm}^{-1}$. A presença dessas bandas são características desse mineral [25]. Ainda que a hematita tenha sido reduzida à magnetita, verifica-se pelos espectros Raman que essa redução não se deu de maneira completa, pois ainda há a presença de algumas bandas de hematita nas três temperaturas estudadas, como é o caso dos modos ativos em 225, 400 e 620 $\mathrm{cm}^{-1}$, os quais são característicos da hematita [25].

As Figuras 7 e 8 apresentam os espectros realizados nas misturas que contêm $40 \%$ de lama vermelha (Figura 7a), 50\% de lama vermelha (Figura 7b), 60\% de lama vermelha (Figura 8a) e 70\% de lama vermelha (Figura 8b). Essas misturas foram submetidas a um tratamento térmico nas temperaturas de 500, 600 e 1000 ${ }^{\circ} \mathrm{C}$ durante $2 \mathrm{~h}$. 


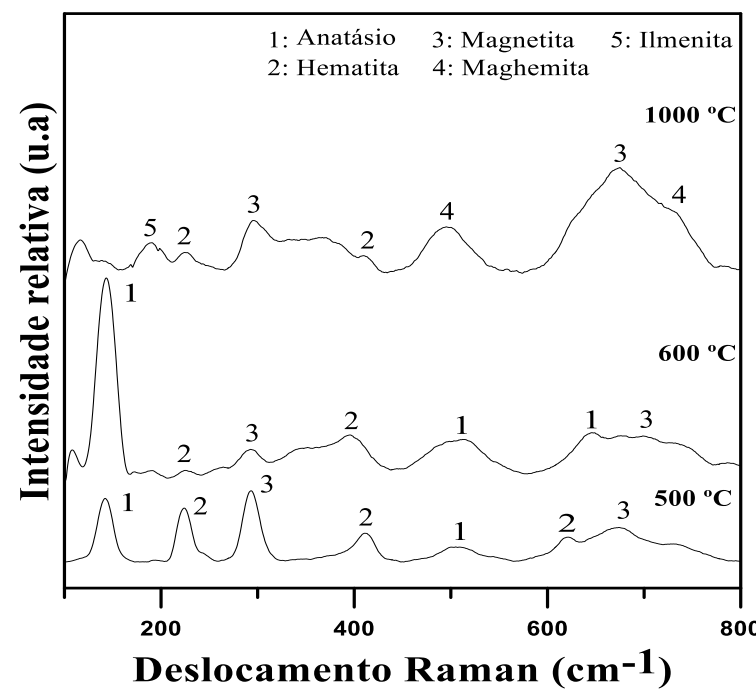

(a)

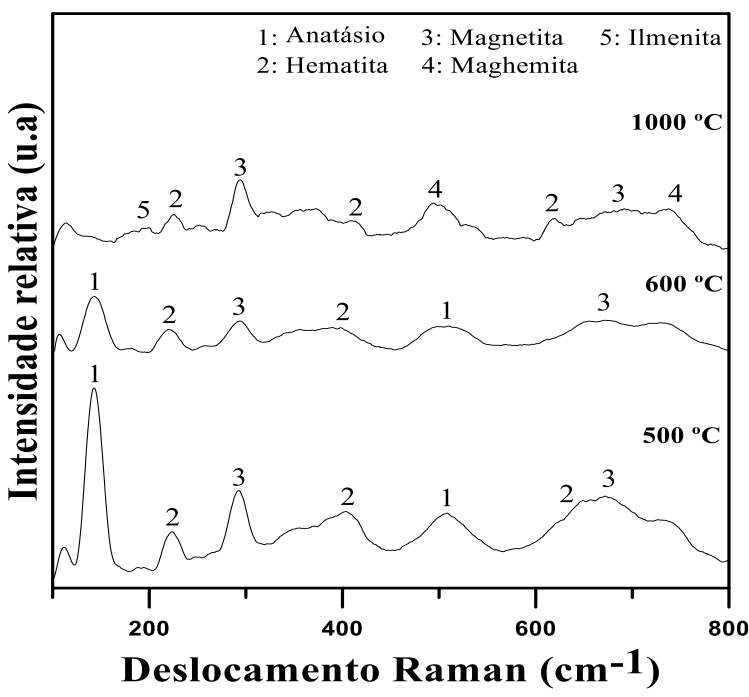

(b)

Figura 7: Espectro Raman do efeito da temperatura para a (a) LV40\% e (b) LV50\%.

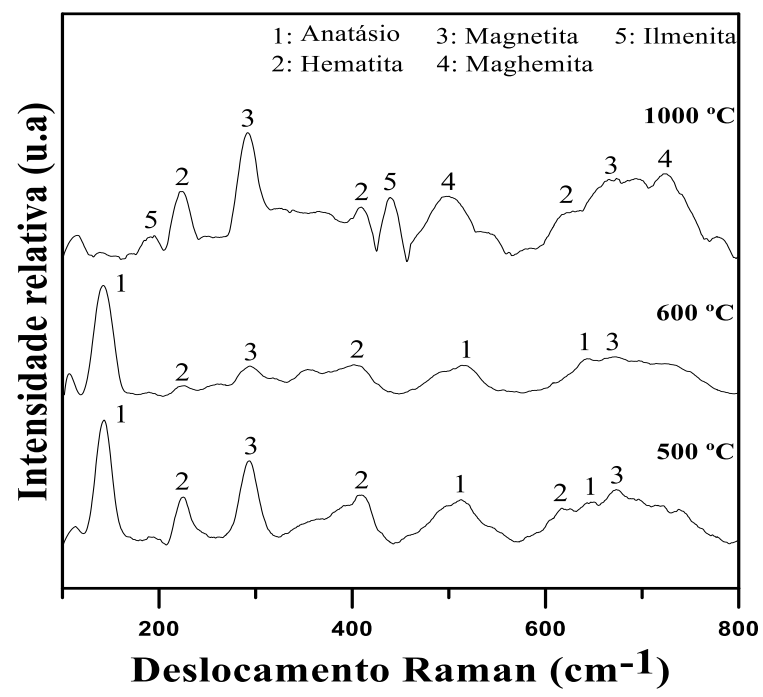

(a)

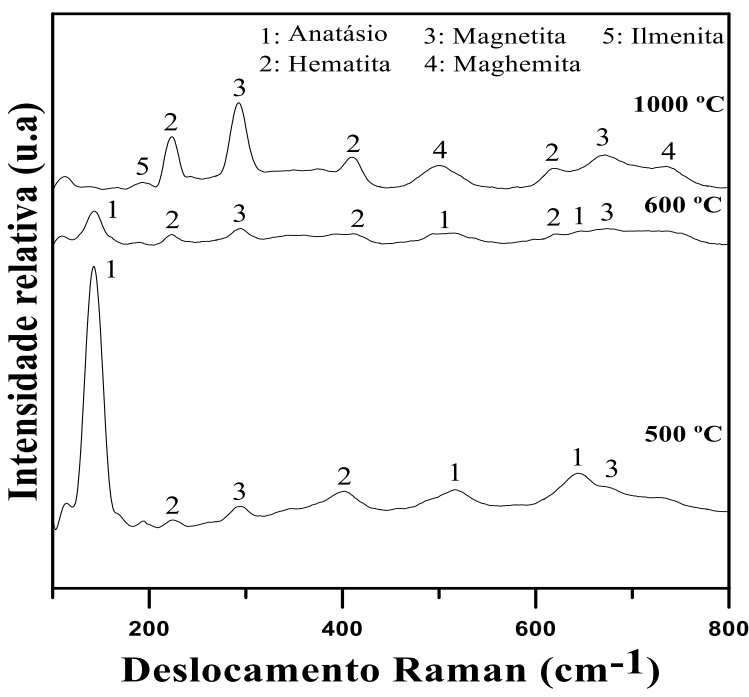

(b)

Figura 8: Espectro Raman do efeito da temperatura para a (a) LV60\% e (b) LV70\%.

Os espectros Raman apresentados nas Figuras 7 e 8 apresentaram comportamento similares aos apresentados anteriormente na Figura 6, apenas com pequenas diferenças na intensidades e sobreposição de picos, como é o caso da banda de magnetita localizada em $670 \mathrm{~cm}^{-1}$ para a LV40\% calcinada a $1000{ }^{\circ} \mathrm{C}$ (Figura 7a). Nota-se que para esse espectro há uma sobreposição dos modos ativos de magnetita $\left(670 \mathrm{~cm}^{-1}\right)$ e maghemita $\left(720 \mathrm{~cm}^{-1}\right)$.

Para as misturas calcinadas a 500 e $600{ }^{\circ} \mathrm{C}$ há a presença do mineral de anatásio. Porém, ao ser calcinada a $1000^{\circ} \mathrm{C}$, ocorre a transformação do anatásio para a ilmenita, a qual é comprovada com a presença do modo ativo em $190 \mathrm{~cm}^{-1}$. Verifica-se também a presença de magnetita em todos os espectros, confirmando o processo de redução da hematita.

\section{CONCLUSÕES}

As análises de difração e fluorescência de raios X mostraram que a lama vermelha é composta majoritariamente por ferro, nas formas de hematita e goethita, e que o titânio está presente em aproximadamente $5 \% \mathrm{em}$ massa, na forma de anatásio. Quando submetida ao processo de calcinação, a goethita sofre desidroxilação para formar a hematita.

As análises de difração de raios $\mathrm{X}$ mostraram também que através de tratamento térmico, nas tempera- 
turas de 500, 600 e $1000{ }^{\circ} \mathrm{C}$ durante $2 \mathrm{~h}$, é possível reduzir a hematita à magnetita, para todas as proporções de lama vermelha e carvão vegetal utilizadas no presente trabalho. O titânio permaneceu livre na mistura, na forma de anatásio, após os processos de calcinação nas temperaturas de 500 e $600{ }^{\circ} \mathrm{C}$. Porém, ao ser calcinada a $1000^{\circ} \mathrm{C}$, o óxido de titânio reage com o ferro dando origem a ilmenita.

A rota tecnológica empregada para todas as proporções de LV e CV nas temperaturas de calcinação de 500 e $600{ }^{\circ} \mathrm{C}$ se mostraram eficiente, pois foi possível reduzir a hematita à magnetita, a qual pode vir a ser extraída do resíduo através de separação magnética ou por lixiviação ácida, fazendo com que aumente a concentração do óxido de titânio (na forma de anatásio) na lama vermelha.

Portanto, estudar um método para a redução da hematita presente na lama vermelha para a forma de magnetita, apresenta-se interessante do ponto de vista ambiental e econômico, pois além de propor um destino adequado ao resíduo, ocorrerá também o reaproveitamento da LV, uma vez que será possível obter duas fases distintas: uma fração rica em ferro, que pode ser utilizada pela indústria siderúrgica, enquanto a outra fração, rica em titânio, pode ser processada para a recuperação do mineral.

\section{AGRADECIMENTOS}

Os autores agradecem ao CNPQ, PPGF/UFPA e aos Laboratório de Caracterização Mineral e Microanálises do Instituto de Geologia da UFPA pelo suporte fornecido a este trabalho.

\section{BIBLIOGRAFIA}

[1] MERCURY, J.M.R., GALDINO, L.G., VASCONCELOS, N.S.L.S., et al., "Estudo do comportamento térmico e propriedades físico-mecânicas da lama vermelha", Revista Matéria, v. 15, n. 3, pp. 445-460, Set. 2010.

[2] MAGAlHÃES, E.M., PASSOS, K.L.M., VIEGAS, B.M., et al., "Mathematical modeling of leaching process of red mud in order to obtain the kinetics parameters", Engenharia Térmica, v. 14, n. 2, pp. 90-94, Dez. 2015.

[3] SILVA FILHO, E.B., ALVES, M.C.M., DA MOTTA, M., "Lama vermelha da indústria de beneficiamento de alumina: produção, características, disposição e aplicações alternativas”, Revista Matéria, v. 12, n. 2, pp. 322-338, Jun. 2007.

[4] WANG, S., ANG, H.M., TADÉ, M.O., "Novel applications of red mud as coagulant, adsorbent and catalyst for environmentally benign processes", Chemosphere, v. 72, n. 11, pp. 1621-1635, Ago. 2008.

[5] WAN-CHAO, L., JIA-KUAN, Y., BO, X., "Recovering iron and preparing building material with residues from Bayer red mud", The Chinese Journal of Nonferrous Metals, v. 1, n. 1, pp. 187-192, Jan. 2008.

[6] LIU, W., YANG, J., XIAO, B., “Application of Bayer red mud iron recovery and building material production from alumosilicate residues”, Journal of Hazardous Materials, v. 161, n. 1, pp. 474-478, Jan. 2009.

[7] XIAO-BIN, L., WEI, X., WEI, L., et al., "Recovery of alumina and ferric oxide from Bayer red mud rich in iron by reduction sintering", Transactions of Nonferrous Metals Society of China, v. 19, n. 5, pp. 13421347, Out. 2009.

[8] QUN-HU, X., YAN-WEI, C., "Experimental study of iron recovering from high iron contained red mud by Bayer process", Journal of Mineralogy and petrology, v. 4, n. 4, pp. 7-12, Abr. 2011.

[9] RAO, M., ZHUANG, J., LI, G., et al., "Iron recovery from red mud by reduction roasting-magnetic separation”, In: Light Metals 2013, TMS Annual Meeting, Minerals, Metals \& Materials Society, pp. 125-130, 2013.

[10] LIU, Y., ZHAO, B., TANG, Y., et al., "Recycling of iron from red mud by magnetic separation after coroasting with pyrite", Thermochimica Acta, v. 588, pp. 11-15, Jul. 2014.

[11] ASSOCIAÇÃO BRASILEIRA DE NORMAS TÉCNICAS, NBR 8112: Carvão vegetal - análise imediata, 1986.

[12] KRIMPALIS, S., PAPADOPOULOS, N. EFTHIMIADIS, K.G., et al., "Magnetic properties in red mud after thermal treatment", Journal of optoelectronics and advanced material, v. 10, n. 5, pp. 1085-1088, Mai. 2008.

[13] MISHRA, B., STALEY, A., KIRKPATRICK, D., "Recovery and utilization of iron from red mud", In: Light Metals 2001, TMS Annual Meeting, Minerals, Metals \& Materials Society, pp. 149-156, 2001.

[14] ALAM, S., DAS, S.K., RAO, B.H., "Characterization of coarse fraction of red mud as a civil engineering construction material”, Journal of Cleaner Production, v. 168, pp. 679-691, Dec. 2017. 
[15] QUARESMA, D.S., et al., "Estudo da sinterização em reator vertical de leito fixo para produção de agregado sintético", Cerâmica, v. 63, n. 366, pp. 169-177, Abr./Jun. 2017.

[16] RAO, Y.K., "A physico-chemical model for reactions between particulate solids occurring through gaseous intermediates. I- Reduction of hematite by carbon", Chemical Enginering Science, v. 29, n. 6, pp. 14351445, Jun. 1974.

[17] SNARS, K., GILKES, R.J., "Evaluation of bauxite residues (red muds) of different origins for environmental applications", Applied clay science, v. 46, n. 1, pp. 13-20, Set. 2009.

[18] KLOPROGGE, J.T., RUAN, H.D., FROST, R.L., "Thermal decomposition of bauxite minerals: infrared emission spectroscopy of gibbsite, boehmite and diaspore", Journal of Materials Science, v. 37, n. 6, pp. 1121-1129, Mar. 2002.

[19] ANTUNES, M.L.P., COUPERTHWAITE, S.J., F. T. DA CONCEIÇÃO, F.T., et al., "Red mud from Brazil: thermal behavior and physical properties", Industrial \& Engineering Chemistry Research, v. 51, n. 2, pp. 775-779, Jan. 2012.

[20] ROCHA JÚNIOR, C.A.F., ANGÉLICA, R.S., NEVES, R.F., "Síntese de zeólitas do tipo faujasita: comparação entre caulim beneficiado e caulim flint", Cerâmica, v. 61, n. 358, pp. 259-268, Jun. 2015.

[21] STRAKA, P., NAHUNKOVA, J., ZALOUDKOVÁ, M., "Analysis of unburned carbon in industrial ashes from biomass combustion by thermogravimetric method using Boudouard reaction", Thermochimica Acta, v. 575, pp. 188-194, Jan. 2014.

[22] PALMER, S.J., FROST, R.L., "Characterisation of bauxite and seawater neutralised bauxite residue using XRD and vibrational spectroscopic techniques", Journal of Materials Science, v. 44, n.1, pp. 55-63, Jan. 2009.

[23] RAGHAVENDER, A.T., HONG, N.H., LEE, K.J., et al., "Nano-ilmenite FeTiO3: Synthesis and characterization", Journal of Magnetism and Magnetic Materials, v. 331, pp. 129-132, Abr. 2013.

[24] SINGH RAMAN, R.K., GLEESON, B., YOUNG, D.J., "Laser Raman spectroscopy: a technique for rapid characterisation of oxide scale layers", Materials Science and Technology, v. 14, n. 5, pp. 373-376, Mai. 1998.

[25] FARIA, D.L.A., SILVA, S.V., OLIVEIRA, M.T., "Raman microspectroscopy of some iron oxides and oxyhydroxides", Journal of Raman Spectroscopy, v. 28, n. 11, pp. 873-878, Nov. 1997.

\section{ORCID}

Bruno Marques Viegas Edilson Marques Magalhães José Antônio da Silva Souza Emanuel Negrão Macêdo
https://orcid.org/0000-0002-2768-652X

https://orcid.org/0000-0003-3056-0757

https://orcid.org/0000-0002-1784-9217

https://orcid.org/0000-0002-4652-8316 